\title{
Model of a building heating system with renewable energy sources
}

\author{
Nicolay Komitov ${ }^{1}$, Nicolay Shopov ${ }^{1}$, and Violeta Rasheva ${ }^{1, *}$ \\ ${ }^{1}$ University of Food Technologies, 26 Maritza Blvd., Plovdiv, Bulgaria
}

\begin{abstract}
The current century is characterized by an increasing use of renewable energy - wind farms, solar parks, bio fuels, etc. Climate change and rising prices of fossil fuels lead to increased investment in renewable energy. This raises the need to examine the impact of various factors on the efficiency of energy production from renewable energy sources. This is related to the development of adequate models and the implementation of appropriate computer systems to manage and control these processes. The present work presents the main aspects of the modelling of a building heating installation using renewable energy sources - a solar photovoltaic panel and a HHO gas generator. The additional energy needed to heat the building is provided by a pellet boiler. An energy balance of the studied building is made taking into account the external and internal temperatures and energy loss. The computer model was developed in order to build a system for process control in the building's heating system.
\end{abstract}

\section{Introduction}

Global energy policy aims at limiting climate change, energy security and competitiveness [1]. Energy consumption in residential sector is a significant component of the total energy consumption in most countries. According to Euro stat [2], households have had a steady contribution of approximately $25 \%$ to the final energy consumption. In Europe, on average $70 \%$ of the energy consumed by households goes to maintain an appropriate home temperature. Improving the energy efficiency in the residential sector presents an effective approach to reduce energy consumption and associated GHG emissions. A number of scientists have worked in this field [3-5].

Space heating can be achieved by means of different types of heating systems and fuels. The use of fossil fuels leads to environmental pollution [6]. In domestic heating with nonefficient stoves and solid fuel boilers and the use of coal containing ash and sulphur and wet wood, pollutants such as sulphur dioxide, nitrogen dioxide, carbon monoxide and fine particulate matter are the main problem in cities. Recently, many energy projects using biomass as a source of energy have been developed. The use of waste to produce energy from biomass means that environmental pollution is almost zero [7-8].

The most efficient and secure way to meet the energy needs of households is decentralized generation of renewable energy, including in our homes. It concentrates

* Corresponding author: v_rasheva@abv.bg 
complex benefits because: avoids loss in energy transportation, avoids costs for building transmission network, and uses clean and inexhaustible resource [9]. All these factors lead to increased investment in renewable energy sources. It is necessary to study the impact of determinants on the efficiency of energy production from renewable energy sources. Articles [10-12] present studies on the use of energy from renewable sources - photovoltaic panels and brown (HHO) gas. This is related to the development of adequate models and the implementation of appropriate computer management and control systems. In [13] the detailed models are discussed along with their validation. The results show that, although most of the models perform similarly, they don't equally reproduce the dynamics. Modelling and simulation of residential HVAC systems energy consumption has been investigated in [14]. Paper [15] provides an algorithm for model predictive control of multifamily buildings. Thermal computer models of buildings with a central heating system are proposed in [16-17]. In view of some features of renewable energy sources (volatility of energy delivered over time, variability of parameters, etc.), it is essential to develop the so-called "Hybrid" energy generation systems - based on traditional and renewable energy sources. A literature review of model-based analyses in field of renewable energy integration and decarbonisation, focusing residential heating is presented in [18]. Different authors [19-20] monitored and investigated heating systems combining solar collectors and heat pumps.

The aim of this paper is to propose a hybrid heating system of a residential building in which heat is generated from combustion of HHO gas and pellets and some of electricity from PV panel and to develop a computer model of this system.

\section{Materials and methods}

The object of modelling is a heating installation of a residential building, located in town of Plovdiv, Bulgaria. The temperature in the heated area is considered to be $19{ }^{0} \mathrm{C}$. The building consists of unheated basement and heated ground floor and 3 residential floors. The building heated area is $513.92 \mathrm{~m}^{2}$ and its heated volume is $1,284.80 \mathrm{~m}^{3}$. The exterior walls are made of bricks and reinforced concrete with external thermal insulation and an area of $584.70 \mathrm{~m}^{2}$. Their overall heat transfer coefficient is $0.48 \mathrm{~W} /\left(\mathrm{m}^{2} \mathrm{~K}\right)$. The windows are wooden with double-pane frame. They have an area of $119.70 \mathrm{~m}^{2}$ and coefficient of heat transfer $-2.32 \mathrm{~W} /\left(\mathrm{m}^{2} \mathrm{~K}\right)$. The roof is sloping with an area of $158 \mathrm{~m}^{2}$ and air layer with average thickness of $2.25 \mathrm{~m}$. Its overall heat transfer coefficient is $0.29 \mathrm{~W} /\left(\mathrm{m}^{2} \mathrm{~K}\right)$. The coefficient of heat transfer through the floor is $0.46 \mathrm{~W} /\left(\mathrm{m}^{2} \mathrm{~K}\right)$.

On the basis of the energy efficiency legislation in force in the EU and in Bulgaria [21], the energy balance of the building under consideration is made and the amount of energy required for building heating is determined.

The heat transfer coefficient at temperature difference $1 \mathrm{~K}$ is defined in $[\mathrm{W} / \mathrm{K}]$ by the expression (1):

$$
H t r=H_{D}+H_{U}
$$

where $H_{D}$ is heat transfer coefficient through envelope elements bordering on outside air at temperature difference $1 \mathrm{~K}[\mathrm{~W} / \mathrm{K}]$;

$H_{U}$ is heat transfer coefficient through envelope elements bordering on unheated zones at temperature difference $1 \mathrm{~K}[\mathrm{~W} / \mathrm{K}]$.

The heat transfer coefficient by ventilation air at temperature difference $1 \mathrm{~K}$ is calculated in $[\mathrm{W} / \mathrm{K}]$ by the expression (2):

$$
H_{v e}=(\rho c)_{a} \Sigma b_{V E, K} * q_{V E, K},
$$

where $(\rho c)_{a}=0.34 \mathrm{Wh} /\left(\mathrm{m}^{3} . \mathrm{K}\right)$ is specific volumetric capacity of the air; 
$q_{V E, K}-$ is monthly average air flow through the element $\mathrm{k}\left[\mathrm{m}^{3} / \mathrm{h}\right]$;

$b_{V E, K}=1-$ is dimensionless flow factor for flow through element $\mathrm{k}$.

The heat loss Qtr by heat transfer is calculated for each month of the heating period in [kWh] by expression (3):

$$
Q t r=1 / 1000 *\left[\left(H_{t r}+\Phi_{g}\right) *\left(\theta_{i, H}-\theta_{e}\right)\right] * t,
$$

where Htr is heat transfer coefficient through the surrounding area elements at temperature difference $1 \mathrm{~K}[\mathrm{~W} / \mathrm{K}]$;

$\Phi g$ - heat flow through the ground at temperature difference $1 \mathrm{~K}$, caused by the thermal inertia of the ground $[\mathrm{W} / \mathrm{K}]$;

$\theta_{i, H}$, - temperature in the heated area in winter mode $\left[{ }^{0} \mathrm{C}\right]$;

$\theta_{e}$ - the average monthly temperature of the ambient air $\left[{ }^{0} \mathrm{C}\right]$;

$t$-duration of the month [h].

The heat loss Qve from ventilation is calculated for each month in [kWh] by the expression (4):

$$
Q v e=1 / 1000 *\left[H_{v e} *\left(\theta_{i, H}-\theta_{e}\right)\right] * t,
$$

The total heat loss Qht for each month is determined in [kWh] by the expression (5):

$$
Q h t=Q t r+Q v e,
$$

The heat gain for the heated zone is calculated in [kWh] by the expression (6):

$$
Q g n=Q i n t+Q s o l,
$$

where Qint is the heat gain from internal heat sources [kWh];

Qsol - the heat gain from the sun [kWh].

The heat gain from appliances and lighting is calculated in $[\mathrm{kWh}]$ by the expression (7):

$$
Q h t=1 / 1000 *\left[\Sigma \Phi_{i n t}, k\right] * t,
$$

where $\Phi$ int, $k$ is the mean time value of the heat flow from the internal source $\mathrm{k}$ [W].

Heat gain from metabolic heat of occupants is calculated by multiplying the number of occupants, the number of hours of residence in the room and the amount of energy emitted by 1 occupant. It is assumed that the occupants are 12 and they occupy the building 12 hours a day and each of them emit average of $65 \mathrm{~W}$.

Energy demand for building space heating in one heating season is calculated in [ $\mathrm{kWh}]$ by the expression (8):

$$
Q_{H, n d}=Q_{H, h t}-\eta_{H, g n} * Q_{H, g n}
$$

where $Q_{H, h t}$ is total heat loss from the building [kWh];

$Q_{H, g n}$ - the heat gain from internal sources and from the sun $[\mathrm{kWh}]$;

$\eta_{H, g n}=0.5$ is a dimensionless factor in the utilization of heat gains.

Thermal energy for the heating system is supplied by the combustion of HHO gas. At lower outside air temperatures, an additional pellet burning boiler is also included if necessary. Both sources heat up the water which is heat carrier of the heating system. The electricity required for the operation of the HHO generator, the pellet boiler and the circulation pumps is supplied by a photovoltaic panel and, if necessary, by the electricity network.

The generator of HHO gas works with an electrolyte of potassium hydroxide and power required for its operation is $191 \mathrm{~W}$. Its mathematical model is developed on the basis of experimental studies. The HHO gas flow is determined in $[1 / \mathrm{h}]$ by the expression (9): 


$$
Q_{\text {gas }}=-10.55 * C_{\text {gas }}+20.07 * I,
$$

where $C_{\text {gas }}$ - is the electrolyte concentration [\%];

$I-$ is the electric current $[\mathrm{A}]$.

The HHO gas combustion boiler has a water jacket and efficiency of $98 \%$. The calorific value of the HHO gas is $6.26 \mathrm{Wh} / 1[11]$.

Water jacket pellet boiler has capacity of $15 \mathrm{~kW}$ and $90 \%$ efficiency. Its pellet consumption is $6 \mathrm{~kg} / \mathrm{h}$ and electricity consumption $-65 \mathrm{~W}$.

The consumption of electricity from the circulation pump of the heating system is $120 \mathrm{~W}$.

The PV panel has a power output of $270 \mathrm{~W}$ at $100 \%$ "load" from solar radiation.

The digital control of the heating system uses a heating system model shown in Fig. 1. The basis of this model is the use of renewable energy sources such as the sun (SP) and the energy generated by the HHO generator $(G)$. Electricity in the presented scheme is provided by two sources - the public electricity network and the energy from photovoltaic panel. The electricity supplies the other energy sources - the HHO generator and the standard pellet boiler (PB). As a result, both sources of energy heat up the water which is a heat carrier of the heating system.

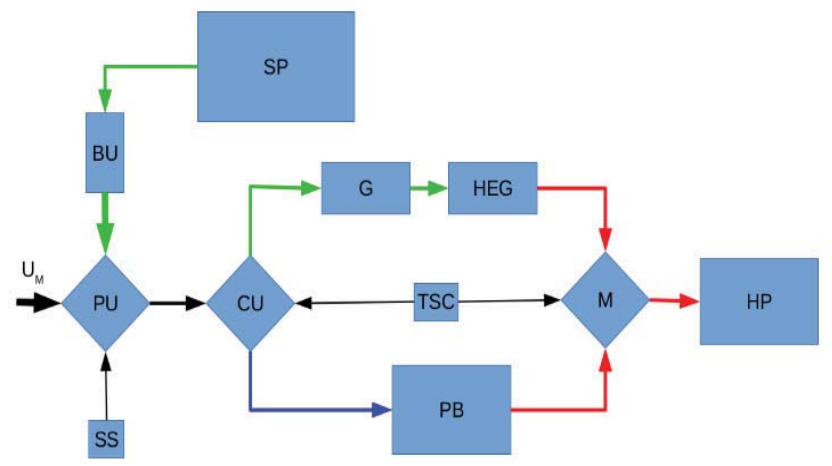

Fig. 1. Principle scheme of digital model for heating system from ,green energy“

SP - PV solar panels, BU - battery unit, PU - power unit, UM - mains voltage, SS - solar sensor, CU control unit, G - HHO generator, HEG - heat exchanger for HHO gas, PB - pellet boiler, M - mixer, TSC - temperature sensor of coolant, HP - heating part (radiators)

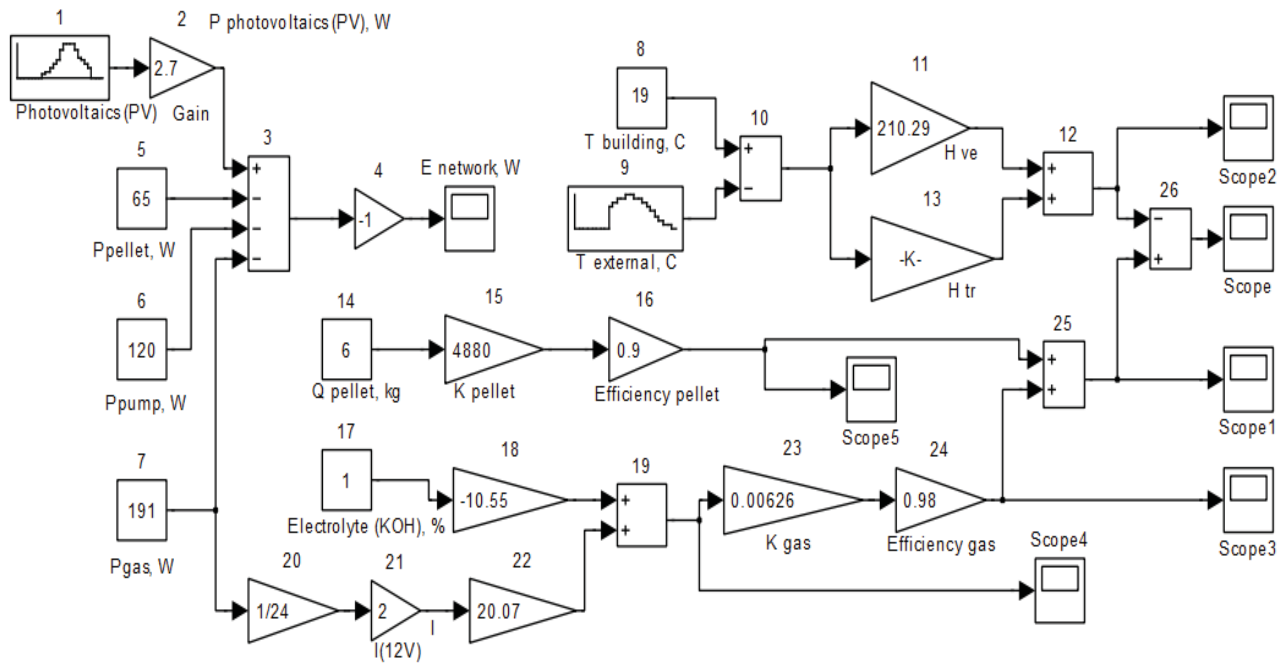

Fig. 2. Model of the heating installation using renewable energy sources 
1 - solar panel load; 2 - solar panel amplifier; 3 - power supply adder; 4 - electricity consumption; 5 - pellet boiler power supply; 6 - circulation pump power supply; 7 - power supply for HHO generator; 8 indoor air temperature; 9 - outside air temperature; 10 - temperature difference generation; 11 and 13 - thermal coefficients of the building; 12 - adder for energy used for heating; 14 - consumption of pellets in pellet boiler; 15 - hot water pellet boiler model; 16 - pellet boiler efficiency; 17 - condition of the electrolyte; 18, 19, 22 - a HHO gas generator regression model; 20, 21 - coefficients of transformation of electric energy; 23 - HHO gas burning boiler model; 24 - HHO gas boiler efficiency; 25- adder of the energy delivered to the building; 26 - adder of energy delivered and losses from the building.

The next step is to develop digital management of the proposed system based on a PLC (Programmable Logic Controller). To develop a control system of the studied energy system is necessary to explore its features. The most appropriate would it be done on artificially created its "copy" - model. For modelling of an object it is necessary to be built and tested models, which are the reflection of the target object. At the same time, the model itself is a complex object, certain features of which correspond to elements of the original. Depending on the degree of compliance, the degree of adequacy of the model is determined. Therefore, as the model is closer copy of the real object, the more accurate the obtained results are.

The model of the studied system is designed in programming environment for modelling and simulation "Mat lab" "Simulink" [22] and is represented in Figure 2.

\section{Calculation of heat demand for building space heating}

The total heat loss $Q_{h t}$ for each month of the heating season, calculated by the expressions (3), (4) and (5) is presented in Table 1.

Table 1. Total heat loss $Q_{h t}$ form building envelope

\begin{tabular}{|c|c|c|c|c|c|c|c|c|c|}
\hline Month & Days & $q_{i, H}$ & $q_{e}$ & $q_{i, H}-q_{e}$ & $H_{t r}$ & $Q_{t r}$ & $H_{v e}$ & $Q_{v e}$ & $Q_{t r}+Q_{v e}$ \\
\hline & number & ${ }^{\circ} \mathrm{C}$ & ${ }^{0} \mathrm{C}$ & ${ }^{0} \mathrm{C}$ & $\mathrm{W} / \mathrm{K}$ & $\mathrm{kWh}$ & $\mathrm{W} / \mathrm{K}$ & $\mathrm{kWh}$ & $\mathrm{kWh}$ \\
\hline 1 & \begin{tabular}{|l|}
31 \\
\end{tabular} & 19 & 0.2 & 18.8 & 653.01 & $9,133.781$ & 210.29 & $2,941.368$ & $12,075.150$ \\
\hline 2 & 28 & 19 & 1.8 & 17.2 & 653.01 & $7,547.751$ & 210.29 & $2,430.616$ & $9,978.367$ \\
\hline 3 & 31 & 19 & 6.9 & 12.1 & 653.01 & $5,878.657$ & 210.29 & $1,893.115$ & $7,771.772$ \\
\hline 4 & 6 & 19 & 12.4 & 6.6 & 653.01 & 620.621 & 210.29 & 199.859 & 820.480 \\
\hline & & & & $\ldots$ & & & & & \\
\hline 10 & 8 & 19 & 12.8 & 6.2 & 653.01 & 777.343 & 210.29 & 250.329 & $1,027.672$ \\
\hline 11 & 30 & 19 & 7.4 & 11.6 & 653.01 & $5,453.940$ & 210.29 & $1,756.342$ & $7,210.282$ \\
\hline 12 & 31 & 19 & 1.9 & 17.1 & 653.01 & $8,307.854$ & 210.29 & $2,675.393$ & $10,983.248$ \\
\hline Total & & & & & & $37,719.947$ & & $12,147.020$ & $49,866.971$ \\
\hline
\end{tabular}

The total heat gain $Q g n$ for each month of the heating season, calculated by the expressions (6), (7) and (8) is presented in Table 2.

Table 2. Total heat gain $Q g n$ form building envelope

\begin{tabular}{|r|c|c|c|c|c|}
\hline Month & \multicolumn{1}{c|}{ Days } & Qint, $M$ apliances & Qint,$M$ occupants & Qi,sol & Qi, gn \\
\hline & number & $\mathrm{kWh}$ & $\mathrm{kWh}$ & $\mathrm{kWh}$ & $\mathrm{kWh}$ \\
\hline 1 & 31 & $1,369.555$ & 580.320 & $2,760.096$ & $4,709.972$ \\
\hline 2 & 28 & $1,237.018$ & 524.160 & $2,947.064$ & $4,708.241$ \\
\hline 3 & 31 & $1,369.555$ & 580.320 & $3,623.305$ & $5,573.180$ \\
\hline 4 & 6 & 265.075 & 112.320 & 759.077 & $1,136.473$ \\
\hline$\ldots \ldots \ldots$ & $\ldots \ldots \ldots$ & $\ldots \ldots \ldots \ldots$ & $\ldots \ldots \ldots \ldots$ & $\ldots \ldots \ldots$ \\
\hline 10 & 8 & 353.434 & 149.760 & 900.581 & $1,403.775$ \\
\hline 11 & 30 & $1,325.376$ & 561.600 & $2,553.375$ & $4,440.351$ \\
\hline 12 & 31 & $1,369.555$ & 580.320 & $2,236.742$ & $4,186.617$ \\
\hline Total & & & & & $26,158.609$ \\
\hline
\end{tabular}




\section{Computer model of building heating system}

According to the solar system integration diagram (PV panel), it is necessary to select the sunshine properly. Block 1 sets the twenty-four hour load (in the range from 0 to 100\%) of the PV panel. The PV panel output is set according to the sunrise and the sunset during the heating season. The management system envisages the use of a photoelectric sensor, which determines the presence of the solar radiation that falls on the panel. The amplifier block 2 takes into account the correlation between the solar radiation encountered on the solar panel and the electrical power generated by the solar panel. The output of the selected PV panel produces a power of $270 \mathrm{~W}$ at $100 \%$ solar radiation load.

The permanent costs of electric power for the purposes of the heating system are reported in the setting blocks (5), (6) and (7). Block (5) records the consumption of electricity by the pellet boiler $(65 \mathrm{~W})$, unit (6) records the consumption of electricity by the circulation pump of the heating system (120W), and unit (7) records the energy required for the operation of the HHO generator. Depending on the operating modes of the heating installation these consumptions may change. The switching logic is determined by the adder (3), and in case of insufficient electricity production by the PV panel it is envisaged to add electricity from the electricity grid. Unit (4) represents the energy consumed from the electricity network. An oscilloscope is fitted to illustrate the obtained results.

The desired temperature setting is realized by blocks $8-13$. In the developed model, the value of the set room temperature $\left(19{ }^{\circ} \mathrm{C}\right)$ is recorded by block $(8)$, and the hourly change in ambient (outside) air temperature is recorded in block (9). The difference between the room temperature and the outside air temperature is obtained at the outlet of the adder (10). The amplifiers (11) and (13) simulate heat transfer to the outside space. Thus presents the heat loss through the building envelope and heat gains through solar radiation. The results are illustrated by means of an oscillograph.

The operating conditions of the HHO generator are set by the power consumer for the HHO generator (7) via the amplifiers (20-22). Together with the selected electrolyte condition for the HHO generator (17) and the amplifier (18), logic sums them according to a certain law and the necessary thermal energy is generated. The heat loss due to the fact that the HHO gas generator efficiency is below $100 \%$ is realized by block (23), and the heat loss from the HHO gas combustion boiler - by block (24). In this way the heating of the building with specified thermal energy consumption is realized.

An alternative option for building heating is the use of a pellet boiler. The condition for the consumption of pellets in the boiler is realized with (14). The combustion process, heat exchange and efficiency of the hot water pellet boiler are represented by the amplifiers (15) and (16). The adder (25) represents the energy received from the pellet boiler and the energy received from the $\mathrm{HHO}$ gas combustion boiler, determining which of the energy sources will be used depending on the solar radiation or the charge of the battery and on the temperature of the outside air.

The adder (26) consumes the heat generated for heating the building according to a particular law and according to the external climatic conditions or the desired internal air temperature. The results are illustrated by means of an oscillograph.

Selected is a solar panel with a nominal power of $270 \mathrm{~W}$, as in block 1 is set hourly diurnal "load" of the panel in the range of $0-100 \%$. The electricity consumed is determined by means of units (5-power supply of hot water pellet boiler), (6-circulation pump power supply) and (7-HHO generator power supply), as the values shown in Figure 2 being in W. The energy consumed from the electrical network is counted using the oscilloscope after the block (4). The model of heat loss from the building and the energy required for heating the building is realized with the help of blocks (8-13). The set value of the building inside air temperature is entered in block (8) and the hourly change of the outside air temperature 
is entered in block (9). This represents the loss of heat through the building envelope and its heating. The results are illustrated by means of an oscilloscope.

The mathematical model of the HHO (Brown) gas generator has been developed on the basis of practical research. Experiments were carried out with electrolyte $\mathrm{KOH}$. The equation can be modelled in the presented in Figure 2 model, as blocks (17) and (18) should be removed, and in block (2) must be introduced coefficient obtained from the experiments.

The model of the boiler for HHO gas burning is realized by blocks (23) and (24), as block (24) takes into account the efficiency of the boiler. The adder (25) represents the energy produced from the pellet boiler and that from the HHO generator, determining which of the energy sources will be used depending on the solar radiation or the battery charge. The energy balance of the heating system is modelled by the adder (26). In it, the heat loss of the building is subtracted from the generated heat energy for heating the building. The results are illustrated by means of an oscilloscope.

\section{Results and discussion}

The validation of the presented computer model of the heating installation is done using data on the change of the ambient air temperature and solar radiation within 24 hours on a cold January day in Plovdiv [23]. The obtained model results are visualized with oscilloscopes. For example, figure 3 shows the power obtained for 24 hours from the PV panel, depending on the daytime solar radiation, and figure 4 shows the power consumed for 24 hours from the electricity network.

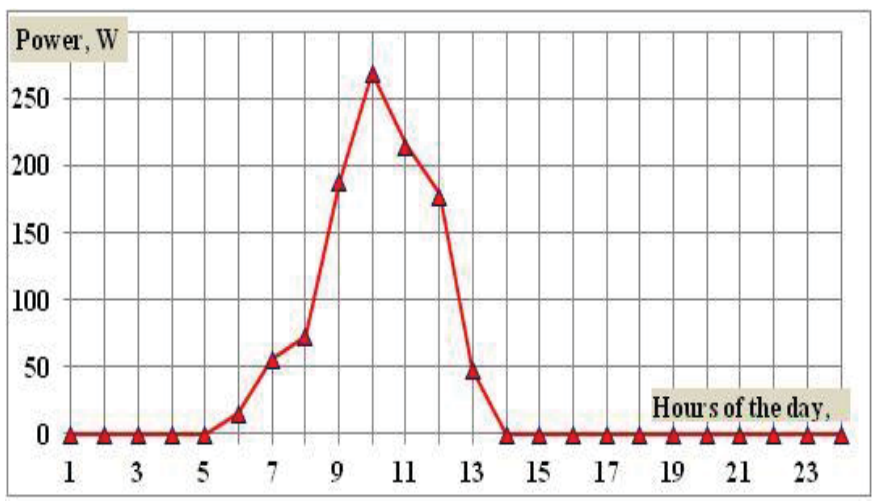

Fig. 3. The power obtained from the PV panel, depending on the daytime solar radiation

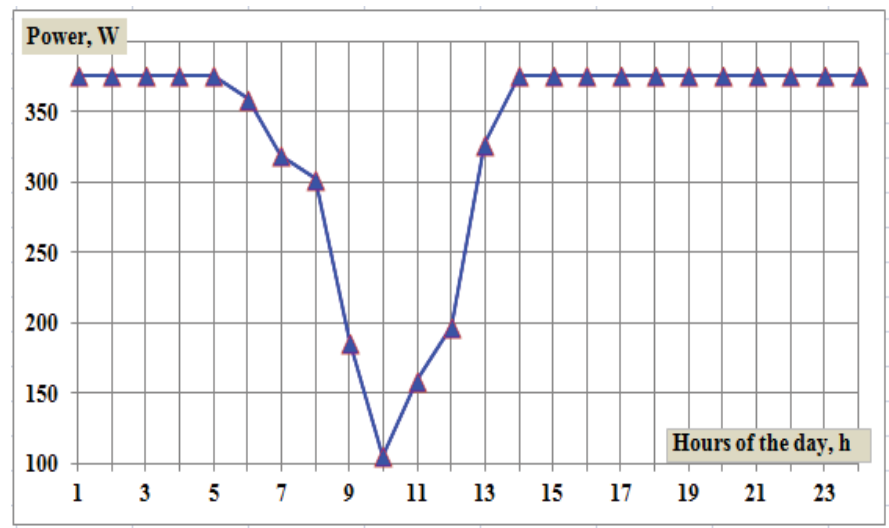

Fig. 4. The power consumed for 24 hours from the electricity network 
Figure 5 shows the temperature difference between the set temperature in the building and the hourly ambient air temperature within 24 hours, and figure 6 shows the heat loss from the building in 24 hours.

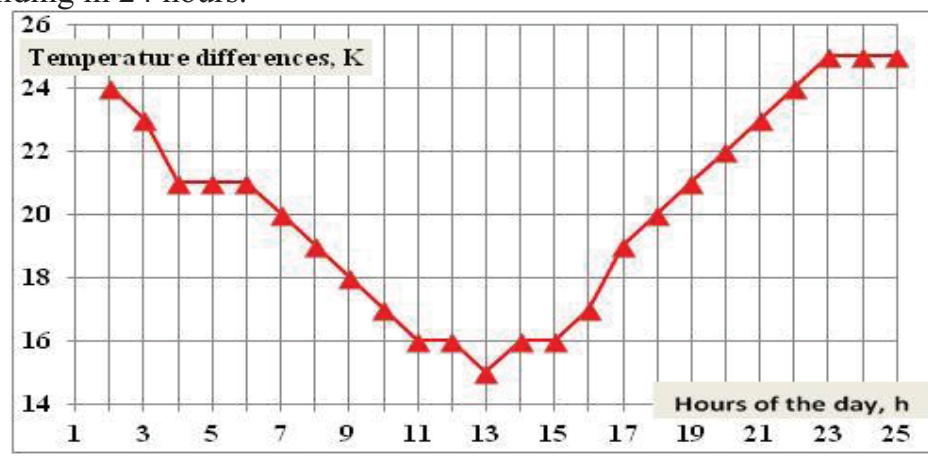

Fig. 5. Temperature difference between the set temperature in the building and the hourly ambient air temperature within 24 hours [K]

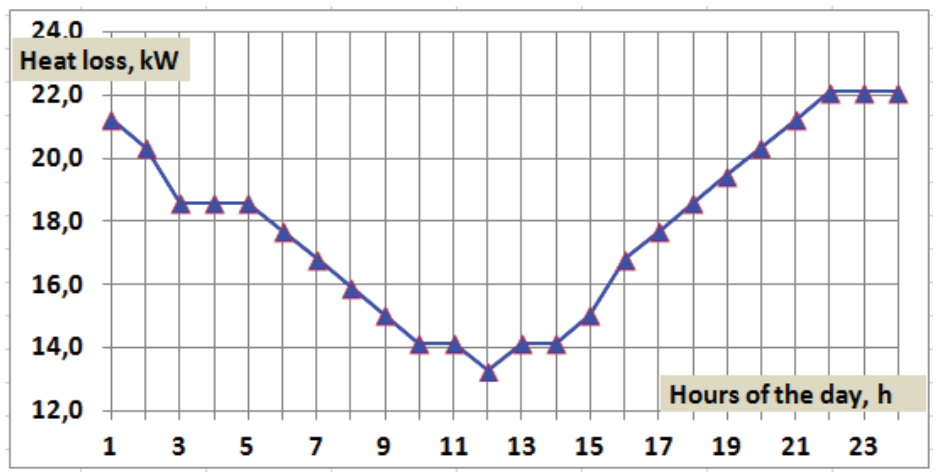

Fig. 6. The heat loss from the building within 24 hours

Figure 7 illustrates the excess heat flow after the heat flow required for the building heating has been consumed, in case when the HHO generator and the pellet boiler are operating simultaneously (energy balance). The result shows that this heat flow is significantly higher than the heat flow required to heat the studied building. Therefore the presented computer model could be used for process control in heat and electricity supply for heating system. Mainly a boiler for HHO gas combustion will work, and in case of too low outside air temperature and lack of heat the pellet boiler will be started.

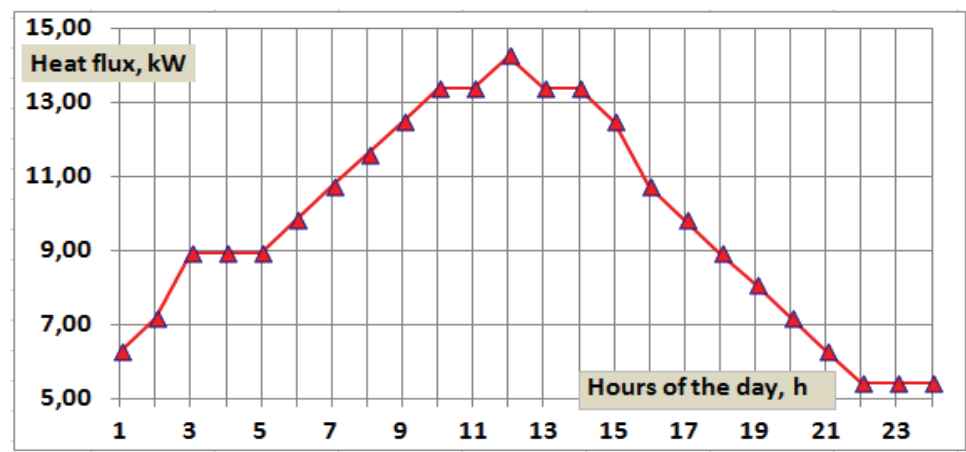

Fig. 7. The excess heat flow after the required for the building heating system heat flow has been consumed, in case when the HHO generator and the pellet boiler are operating simultaneously 


\section{Conclusions}

An energy balance of the studied building is carried out and the thermal energy required for hot water building heating installation is determined. Thermal energy is supplied by the combustion of $\mathrm{HHO}$ gas or by a pellet burning boiler. Electricity is supplied by PV panel or from the power grid, when required.

A computer model of the above described heating system using renewable energy sources is developed. The model gives the possibility of logic choice of the energy source, depending on the outside air temperature, the desired temperature of the heated building and the solar radiation.

\section{References}

1. United Nations. Paris Agreement 2015 - http://unfccc.int/files/essential_background/ convention/application/pdf/english_paris_agreement.pdf $>$.

2. https://climatepolicyinfohub.eu/node/71/pdf

3. S. Lechtenbohmer, A. Schuring, The potential for large-scale savings from insulating residential in the EU, Energy Efficiency 4 (2), 257-70 DOI: 10.1007/s12053-0109090-6 (2011)

4. G. Valchev, Energy efficiency and environmental protection Scientific Conference University of Canakkale, Turkey (2010)

5. P. Zlateva, K. Yordanov, Comparative analysis of the study of microclimate parameters in wooden houses in North-Eastern Bulgaria, IOP Conf. Ser.: Mater. Sci. Eng. 595012017 doi:10.1088/1757-899X/595/1/012017 (2019)

6. B. Angelov, D. Kunev, T. Totev, Contamination of the environment with mercury in the burning of Bulgarian lignite, Energy Forum IHS, Varna, 10-18 (2018)

7. G. Komitov, D. Kehajov, Machines for gathering and utilization of residual biomass from tobacco production, AgroLife, Scientific Journal, 5 Number 1, ISSN 2285-5718 (2016)

8. G. Komitov, I. Ivanov, D. Kehayov, Digital model of heating system from "green energy", Scientific Papers, Serie E, Land Reclamation, Earth Observation \& Surveying, Environmental Engineering, Vol. VII, Bucharest, 247-50 (2018)

9. Energy strategy of the republic of Bulgaria until 2020 - http://www.mi.government.bg/ files/useruploads/files/epsp/22_energy_strategy 2020_.pdf

10. P. Minkov, D. Dimov, Influence of placement of photovoltaic panels on the generated power, Scientific Works of the University of Ruse, Vol. 51, series 3.1 (2012)

11. I. Mitkov, G. Komitov, Possibilities of using HHO generator as renewable energy for buildings heating, Sientific Works of University of Ruse "Angel Kantchev", Ruse, ISSN 1311-3321, Vol. 56, series 1.1, Ruse 73-78 (2017)

12. D. Kehayov, G. Komitov, I. Ivanov, Influence of some factors on the gas flow produced by HHO generator, Scientific Papers, Series E, Land Reclamation, Earth Observation \& Surveying, Environmental Engineering, Vol. VIII, Print ISSN 2285-6064, CD-ROM ISSN 2285-6072, Online ISSN 2393-5138, ISSN-L 2285-6064, 188-91 (2019)

13. I. H. Arcea, S. H. Lópeza, S. L. Pereza, M. Rämäb, K. Klobutb, J. A. Febresa, Models for fast modelling of district heating and cooling networks Renewable and Sustainable, Energy Reviews, 82, 1863-73 (2018)

14. M. Kassas, Modelling and simulation of residential HVAC systems energy consumption, Procedia Computer Science, 52, 754 - 63(2015) 
15. M. Martins, J. Dzintars, N. Stanchioff, Predictive control of a building heating system, Energy Procedia, 113, 501-508,(2017)

16. M. Garcia-Sanz, A reduced model of central heating systems as a realistic scenario for analyzing control strategies Appl. Math. Modelling, 21, 535-45, https://doi.org/10.1016/S0307-904X(97)00082-6 (1997)

17. K. Saurav, V. Chandan, Gray-box approach for thermal modelling of buildings for applications in district heating and cooling networks, ACM ISBN 978-1-4503-2138-9. DOI: $10.1145 / 3077839.3084078,347-52$ (2017)

18. A. Bloessa, W. f-P Schillb, and A. Zerrahnb, Power-to-heat for renewable energy integration: A review of technologies, modelling approaches, and flexibility potentials, Applied Energy, 212, 1611-26 (2018)

19. D. Testi, E. Schito, E. Tiberi, P. Conti, W. Grassi, Building energy simulation by an inhouse full transient model for radiant systems coupled to a modulating heat pump, Energy Procedia, 78, 1135-40 (2015)

20. C. Fraga, F. Mermoud, P. Hollmuller, E. Pampaloni, B. Lachal, Large solar assisted heat pump systems in collective housing: in-situ monitoring results for summer season, Energy Procedia, 48, 1086-95 (2014)

21. Regulation № 7 of 2004 on Energy Efficiency of Buildings https://www.mrrb.bg/bg/normativni-aktove/naredbi/page/5/

22. U. Lazarev, Modelling processes and systems in MATLAB. Training course. Kiev: BHV Publishing Group, Ukraine (2005)

23. Photovoltaic geographical information system - https://re.jrc.ec.europa.eu/pvg_tools/ en/tools.html\#MR 